\title{
Cell wall and organelle modifications during nitrogen starvation in Nannochloropsis oceanica F\&M-M24
}

\author{
Bianca Roncaglia ${ }^{1}$ - Alessio Papini ${ }^{2} \cdot$ Graziella Chini Zittelli $^{3} \cdot$ Liliana Rodolfi $^{1} \cdot$ Mario R. $^{\text {Tredici }}{ }^{1}$
}

Received: 10 August 2020 / Revised and accepted: 8 February 2021 / Published online: 1 March 2021

(C) The Author(s) 2021, corrected publication 2021

\begin{abstract}
Nannochloropsis oceanica F\&M-M24 is able to increase its lipid content during nitrogen starvation to more than $50 \%$ of the total biomass. We investigated the ultrastructural changes and the variation in the content of main cell biomolecules that accompany the final phase of lipid accumulation. Nitrogen starvation induced a first phase of thylakoid disruption followed by chloroplast macroautophagy and formation of lipid droplets. During this phase, the total amount of proteins decreased by one-third, while carbohydrates decreased by $12-13 \%$, suggesting that lipid droplets were formed by remodelling of chloroplast membranes and synthesis of fatty acids from carbohydrates and amino acids. The change in mitochondrial ultrastructure suggests also that these organelles were involved in the process. The cell wall increased its thickness and changed its structure during starvation, indicating that a disruption process could be partially affected by the increase in wall thickness for biomolecules recovery from starved cells. The wall thickness in strain F\&M-M24 was much lower than that observed in other strains of $N$. oceanica, showing a possible advantage of this strain for the purpose of biomolecules extraction. The modifications following starvation were interpreted as a response to reduction of availability of a key nutrient (nitrogen). The result is a prolonged survival in quiescence until an improvement of the environmental conditions (nutrient availability) allows the rebuilding of the photosynthetic apparatus and the full recovery of cell functions.
\end{abstract}

Keywords Nannochloropsis oceanica $\cdot$ Ultrastructure $\cdot$ Electron microscopy $\cdot$ Lipid accumulation $\cdot$ Nitrogen starvation

\section{Introduction}

One of the most investigated fields of algae biotechnology is biofuels production (Milano et al. 2016). Microalgae cultivation belongs to the so-called second (Papini and Simeone 2010) or third generation biofuels (Brennan and Owende 2010). There are several reasons that make microalgae better candidates than land crops: first of all, microalgae photosynthetic yield is higher than that of many land crops, and some microalgal species manage to stock up to more than $60 \%$ of

Alessio Papini

alpapini@unifi.it

1 Dipartimento di Scienze e Tecnologie Agrarie, Alimentari, Ambientali e Forestali, Università di Firenze, Piazzale delle Cascine, 18 - 50144, Florence, Italy

2 Dipartimento di Biologia, Università di Firenze, Via Micheli 3, 50121 Florence, Italy

3 CNR - Institute of BioEconomy, Via Madonna del Piano 10, 50019 Sesto Fiorentino, Florence, Italy their dry weight in lipids. Moreover, they can be grown in wastewater, brackish and sea waters and thus, they are not competing for fresh water or arable lands with agricultural crops (Ndimba et al. 2013; Slade and Bauen 2013). In addition, their reserves of lipids mainly consist in triglycerides (TAGs) that can be easily converted into biodiesel by transesterification (Bondioli et al. 2012). Their metabolism can be easily controlled and manipulated through changes in growth conditions that lead to an increase in their lipid content.

Nutritional stress strongly influences microalgal metabolism, inducing changes in photosynthesis and in the stocking of lipids; and nitrogen $(\mathrm{N})$ starvation is considered particularly effective to achieve high lipid contents (Bondioli et al. 2012; Rios et al. 2015). Nitrogen starvation affects the photosynthetic mechanism by reducing both the response of light harvesting and the photochemical use of absorbed energy (Simionato et al. 2013). This is because of a depletion of photosynthetic complexes as well as in the chlorophyll (Chl) content, and this inhibition of photosynthesis eventually stops growth in favour of the accumulation of TAGs. There are several microalgal species that have been studied for their ability to stock lipids under nutritional stress; among these, the genus Nannochloropsis is the most promising. 
Nannochloropsis belongs to the Eustigmatophyceae and it is composed of species living in a wide range of environments (marine, fresh and brackish waters) and its cells range in size from 2 to $5 \mu \mathrm{m}$. It has been shown that under nitrogen starvation, cells of this genus can accumulate more than $60 \%$ of their dry weight in lipids (Rodolfi et al. 2009; Dong et al. 2013) that is why it has been widely studied for biodiesel production both in outdoor and indoor growth conditions. Starvation in Nannochloropsis produces changes in proteome, shifting the metabolism towards nitrogen recycling and lipid accumulation (Hong-Po et al. 2013).

The large amount in lipids, particularly in poly-unsaturated fatty acids, is considered relevant also for the use of Nannochloropsis spp. as functional food and for marine fish larvae nutrition (Zanella and Vianello 2020). However, besides the high lipid yield, Nannochloropsis cells are characterised by a hard and robust wall, which makes it difficult to break the cell and extract the oil, considerably increasing the cost of the extraction process (Long and Abdelkader 2011; McMillan et al. 2013). Several attempts have been made to reduce the resistance of the cell wall to mechanic disruption such as anaerobic induction of cell wall rupture by polysaccharide disruption (Halim et al. 2019). An ultrastructural analysis by electron microscopy of the changes that occur at the cell wall level during starvation could help understanding how to improve the extraction of usable cell components.

In this study we characterised Nannochloropsis oceanica F\&M-M24 ultrastructure after nitrogen starvation, in two different growth conditions. The first one was carried out in open ponds under natural light (outdoors); the second one was performed indoors, under artificial light. We observed that in both conditions, the cell ultrastructure changed significantly as a consequence to nitrogen starvation, with major changes affecting the photosynthetic apparatus and the structure of the cell wall.

The main aims of the investigation were to provide detailed evidence of the ultrastructural changes following lipid accumulation and of the cell wall changes during the starvation process that is commonly used prior to the alga collection and lipid extraction.

\section{Materials and methods}

\section{Organism and growth conditions}

For both experiments Nannochloropsis oceanica F\&M-M24 from the Microalgae Culture Collection of Fotosintetica \& Microbiologica S.r.l. was grown in $f$ medium (Guillard and Ryther 1962) prepared from artificial seawater salts (Adriatic Sea Aquarium \& Equipment, Rimini, Italy) at $30 \mathrm{~g} \mathrm{~L}^{-1}$ salinity. The artificial seawater was filtered through $60-10-1 \mu \mathrm{m}$ melt-blown polypropylene cartridges (for outdoor cultures) or autoclaved (for indoor cultures) and then added with sterile nutrient solutions, except for $\mathrm{NaNO}_{3}$, which was not added in order to achieve nitrogen starvation. For the indoor experiment, the algae inoculum was maintained in $200-\mathrm{mL}$ Erlenmeyer flasks, while the inoculum used for the outdoor experiment was grown in $0.6-\mathrm{L}$ glass tubes under artificial light.

\section{Outdoor experiments}

Experiments aimed at inducing lipid accumulation outdoors were carried out in four small Plexiglas raceway ponds of a surface area of $0.17 \mathrm{~m}^{2}$, containing $10 \mathrm{~L}$ of culture volume, each. The ponds had a dark bottom and lateral surfaces covered with aluminium foils. The experiments were carried out at the experimental area of Fotosintetica \& Microbiologica S.r.l. in Sesto Fiorentino (Florence, Italy) (Lat $43^{\circ} 48^{\prime} 56.4^{\prime \prime} \mathrm{N}$; Long $\left.11^{\circ} 11^{\prime} 59.7^{\prime \prime} \mathrm{E}\right)$. In this paper, results obtained with batch cultures are reported. The cultures were maintained in a $\mathrm{pH}$ range of 7.7-7.8 by $\mathrm{CO}_{2}$ injection on demand. Culture temperature varied according to the environmental conditions and a control unit prevented it from exceeding the value of $30^{\circ} \mathrm{C}$.

Experimental cultures were inoculated so as to start at a concentration of $0.4 \mathrm{~g} \mathrm{~L}^{-1}$ and growth was followed for 8 days.

Culture growth was estimated by measuring the daily change of dry biomass concentration. Daily global solar radiation on the horizontal surface was obtained from LaMMA Agrometeorological Station (CNR-IBE, Sesto Fiorentino, Italy).

\section{Indoor experiments}

The indoor experiments were carried out in 0.7-L glass tubes, with a height of $50 \mathrm{~cm}$ and a diameter of $5 \mathrm{~cm}$. The tubes were illuminated from one side with fluorescent lamps (PHILIPS Master TL5 HO 39W/865) providing a continuous light intensity of $500 \mu \mathrm{mol}$ photons $\mathrm{m}^{-2} \mathrm{~s}^{-1}$ at the tube surface. An air: $\mathrm{CO}_{2}$ mixture $(98: 2 \mathrm{v} / \mathrm{v})$ was bubbled in the cultures to provide carbon, to ensure mixing, gas exchange and to adjust $\mathrm{pH}$, which was monitored daily. The cultures were inoculated at a concentration of $0.55 \mathrm{~g} \mathrm{~L}^{-1}$ for the control culture (integrated with $0.6 \mathrm{~g} \mathrm{~L}^{-1}$ of $\mathrm{NaNO}_{3}$ ) and of $0.71 \mathrm{~g} \mathrm{~L}^{-1}$ for the nitrogen starved one and were run in batch for 8 days. Culture growth was estimated by measuring the dry biomass concentration.

\section{Growth and biomass analyses}

Growth of the cultures was estimated by daily measurement of the dry biomass concentration. For dry weight determination, triplicate culture samples $(2-5 \mathrm{~mL})$ were diluted (1:5) with 
Fig. 1 Growth (lines) and volumetric productivity (bars) of N. oceanica F\&M-M24 cultivated indoors in tubes under nutrientsufficient conditions (control culture) and under nitrogen starvation. For days 4-5-6, volumetric productivity was derived over multiple days

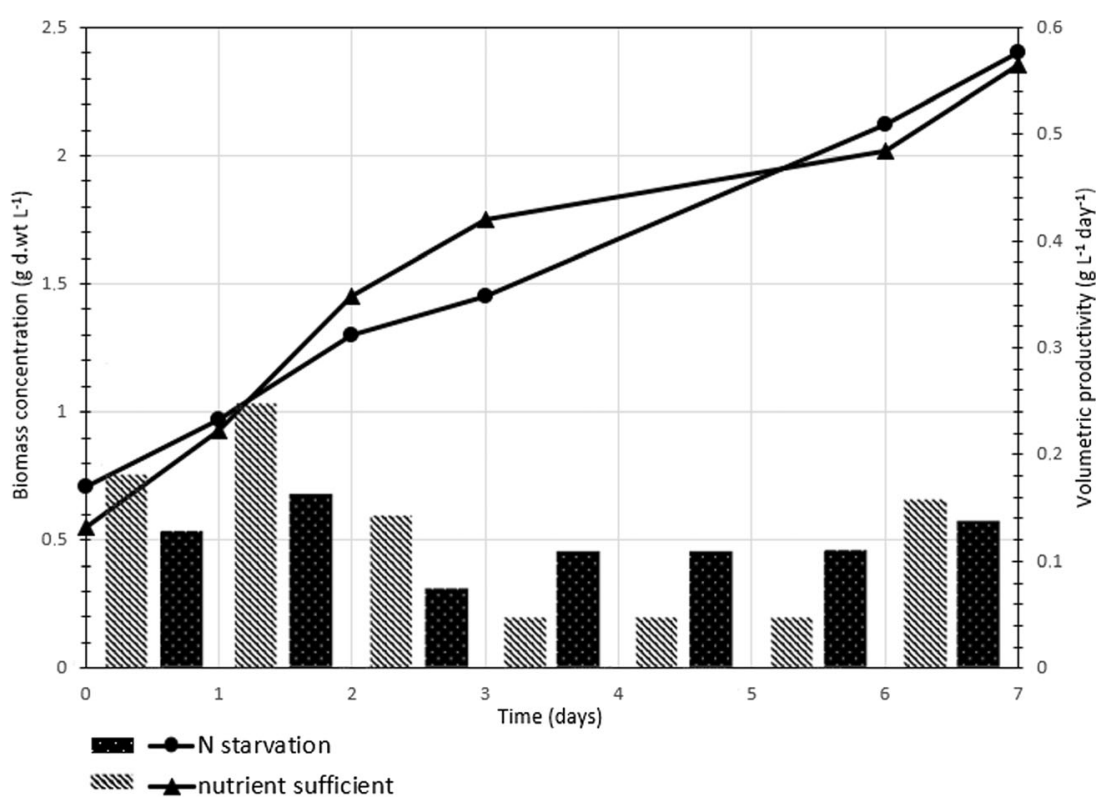

distilled water and filtered through pre-weighed 1.2- $\mu \mathrm{m}$ glass-fibre filters (Whatman $\mathrm{GF} / \mathrm{C} ; 47 \mathrm{~mm}$ ). The filtered cells were washed with distilled water and dried at 105 ${ }^{\circ} \mathrm{C}$ to constant weight.

Volumetric productivity (as $\mathrm{g} \mathrm{L}^{-1}$ day $^{-1}$ ) was calculated by the difference between the biomass concentration values between two sampling dates, divided by the number of days between samplings. In outdoor experiments to achieve areal productivity, the volumetric productivity was multiplied by the culture volume and divided by the surface area of the ponds.

For outdoor cultures, aliquots of $200 \mathrm{~mL}$ were collected daily at the end of the night to conduct the analyses. For indoor cultures, a sample of $50 \mathrm{~mL}$ was collected every 2 days. The collected culture aliquots were centrifuged at $6000 \mathrm{rpm}$ for $10 \mathrm{~min}$ and then washed with a saline solution at a concentration of $9 \mathrm{~g} \mathrm{~L}^{-1}$. The collected biomass was stored at $-20^{\circ} \mathrm{C}$ and then freeze-dried before performing biochemical analyses.

Lipid content was determined spectrophotometrically after carbonisation of the material extracted with a 2:1 methanol/ chloroform solution according to Marsh and Weinstein (1966). Tripalmitin (Sigma-Aldrich, Italy) was used as standard. Lipid concentration was calculated from dry biomass

Table 1 Biochemical composition of $N$. oceanica F\&M-M24 (average $\pm \mathrm{SD} ; n=4)$ indoor culture under nitrogen starvation. Data are reported as $\%$ of dry biomass

\begin{tabular}{llll}
\hline Day & Lipid (\%) & Protein $(\%)$ & Carbohydrate $(\%)$ \\
\hline 0 & $23 \pm 0.63$ & $43.1 \pm 1.35$ & $17.2 \pm 0.7$ \\
3 & $58.4 \pm 1.5$ & $27.5 \pm 0.72$ & $18.8 \pm 0.29$ \\
8 & $59.8 \pm 1.59$ & $25.4 \pm 0.3$ & $16.7 \pm 0.11$ \\
\hline
\end{tabular}

concentration and lipid content. Carbohydrates and proteins were extracted and quantified according to Dubois et al. (1956) and Lowry et al. (1951), respectively, starting from lyophilised biomass. Biochemical analyses were all conducted in triplicate.

\section{Electron microscopy}

The cells of $N$. oceanica F\&M-M24 were collected with the growth medium and fixed overnight in $1.25 \%$ glutaraldehyde in filtered sea water at $4{ }^{\circ} \mathrm{C}$, then post-fixed in $1 \% \mathrm{OsO}_{4}$ in $0.1 \mathrm{M}$ phosphate buffer $(\mathrm{pH} 6.8)$ for 1 h. After dehydration in an ethanol series and a propylene oxide step, the samples were embedded in Spurr's epoxy resin (Spurr 1969). At each step, the cells were sedimented with a 5 -min centrifuge step at $1500 \mathrm{rpm}$ and only the sediment was used for the following step in order to substitute safely the various solvents with micropipettes without losing cells, as in Capelli et al. (2017) and Papini et al. (2017, 2018).

Transverse sections approximately $80 \mathrm{~nm}$ thick were cut with a diamond knife and a Reichert-Jung ULTRACUT ultramicrotome. The sections were stained with uranyl acetate and lead citrate, and then examined with a Philips EM201 TEM at $80 \mathrm{kV}$. Semi-thin sections were observed with a Leica microscope DM RB Fluo with immersion oil.

The wall thickness was measured on the TEM pictures. A Student's $t$ test was employed to assess the significancy of the different wall thickness in the starved and in the medium grown cells. The test was executed with the software PAST 3.16 (Hammer et al. 2001). 
Fig. 2 Growth curve and areal productivity of $N$. oceanica F\&M-M24-starved culture cultivated outdoors in ponds during spring. Global solar radiation is also reported

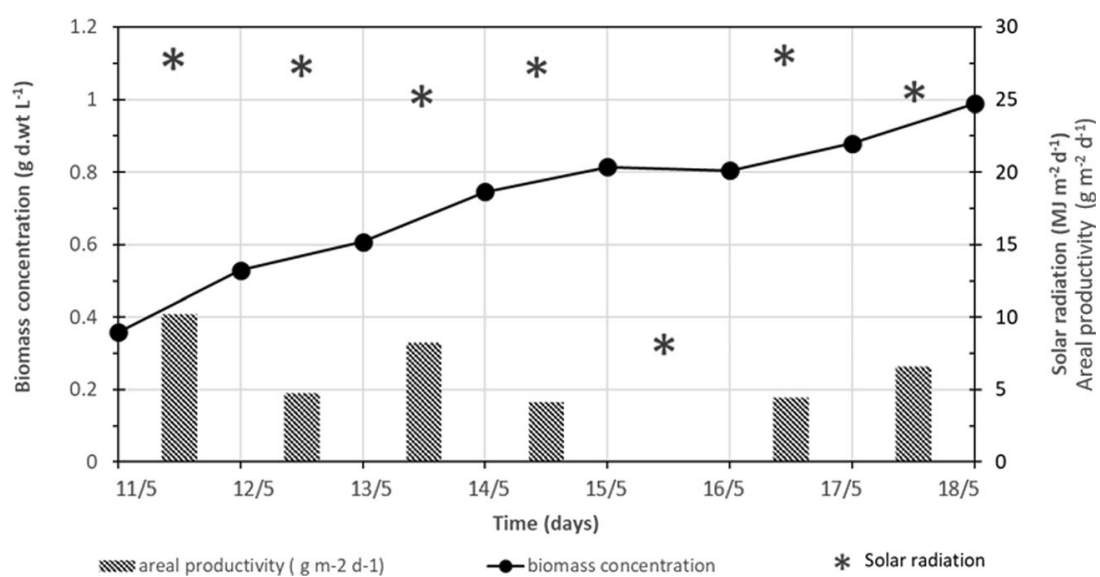

\section{Results}

\section{Indoor cultivation of N. oceanica F\&M-M24: growth and biochemical composition}

The growth curve and volumetric productivity of $N$. oceanica F\&M-M24 cultivated indoors in glass tubes under nutrient sufficient conditions (control culture) and under nitrogen starvation are shown in Fig. 1.

During the week of cultivation, an average biomass productivity of $0.24 \mathrm{~g} \mathrm{~L}^{-1}$ day ${ }^{-1}$ and of $0.26 \mathrm{~g} \mathrm{~L}^{-1}$ day $^{-1}$ was attained respectively for the $\mathrm{N}$-starved culture and for the nutrient-sufficient culture.

The initial lipid content of the biomass was about $23 \%$ and increased up to almost $60 \%$ after 1 week of cultivation. As shown in Table 1, after 3 days of starvation, the lipid content was already over $58 \%$.

The total protein content at the start was $43.1 \%$ and decreased slowly to 25.4. Carbohydrates remained stable at around $17 \%$.

\section{Outdoor cultivation of $N$. oceanica F\&M-M24 under N starvation: growth and biochemical composition}

The growth curve of $N$. oceanica F\&M-M24 cultivated outdoors in ponds under nitrogen starvation is shown in Fig. 2,

Table 2 Biochemical composition of $N$. oceanica F\&M-M24 (average $\pm \mathrm{SD} ; n=3$ ) outdoor culture under nitrogen starvation. Data are reported as $\%$ of dry biomass

\begin{tabular}{llll}
\hline Day & Lipid (\%) & Protein $(\%)$ & Carbohydrate (\%) \\
\hline $11 / 05(0)$ & $31.4 \pm 0.16$ & $39.7 \pm 2.3$ & $17.6 \pm 1.64$ \\
$12 / 05(1)$ & $37.1 \pm 0.55$ & $38 \pm 1.74$ & $14.5 \pm 0.25$ \\
$15 / 05(4)$ & $49.5 \pm 1.06$ & $31 \pm 1.02$ & $15.4 \pm 0.92$ \\
$18 / 05(7)$ & $53 \pm 0.33$ & $26.4 \pm 0.49$ & $15.2 \pm 0.38$ \\
\hline
\end{tabular}

together with the areal productivity obtained and the daily solar radiation received on the culture surface.

During the week of cultivation under $\mathrm{N}$ deficiency, an average productivity of $5.5 \mathrm{~g} \mathrm{~m}^{-2}$ day $^{-1}$ was attained. The highest productivity was observed on the first day $\left(10.2 \mathrm{~g} \mathrm{~m}^{-2} \mathrm{day}^{-1}\right)$ and the culture continued to grow for the following 6 days with an average productivity of $4.7 \mathrm{~g} \mathrm{~m}^{-2}$ day $^{-1}$. The starved batch culture was harvested at the end of the 7th day and the biomass was stored at $-20^{\circ} \mathrm{C}$ for analyses.

The initial lipid content of the biomass was about $31 \%$ and increased gradually up to almost $53 \%$ after 1 week of cultivation (Table 2). The data clearly show the effect of nitrogen deprivation on lipid accumulation and confirm previous results with the same strain (Rodolfi et al. 2009; Bondioli et al. 2012).

The total protein content at the start was about $40 \%$ and decreased slowly to $26.4 \%$, with a reduction of more than $30 \%$. Carbohydrates showed a fast, but low reduction in content remaining stable around $15 \%$ (Table 2).

As regards the pigments, there was a significant drop in the chlorophyll $a$ content, which was reduced by more than $50 \%$ after 3 days of starvation (from 3.9 to $1.7 \%$ ) (data not shown). This is also confirmed by electron microscope analyses, which show the breakdown of the photosynthetic apparatus.

\section{Transmission electron microscopy}

Light microscope images of the grown cultures are provided in the supplementary material (Fig. 1S).

In the control of the indoor cultivation, the chloroplasts showed completely formed thylakoids (Fig. 3a). Four to six small vacuoles in a single section (observation on 20 cells) were present, some of them close to the plasma membrane (Fig. $3 \mathrm{a}$ and $3 \mathrm{~b}$ ). The nucleus was about $1 \mu \mathrm{m}$ long (Fig. $3 b)$. The vacuoles could contain small membrane profiles and dark masses (Fig. 3b). Few lipid droplets (one or two in 
Fig. 3 Nannochloropsis control indoor cultivation. a The chloroplast (arrow) has completely formed thylakoids. 4-6 small vacuoles are present. Some of them close to the plasma membrane. Bar $=1 \mu \mathrm{m}$. $\mathbf{b}$ The nucleus is about $1 \mu \mathrm{m}$ long. The vacuole contains membrane profiles (arrow) and a dark mass. Lipid droplets about 3-400 $\mathrm{nm}$ of diameter are present. $B a r=250 \mathrm{~nm}$. c A double layer of $30.7 \mathrm{~nm}$ in average surrounds the plasma membrane. Mitochondria have tubular cristae and are often close to the plasma membrane. Bar $=$ $500 \mathrm{~nm}$. Key to labelling: c, chloroplast; er, endoplasmic reticulum; L, lipid droplet; LV, lamellate vesicle; $\mathrm{m}$, mitochondrion; $n$, nucleus; $v$, vacuole
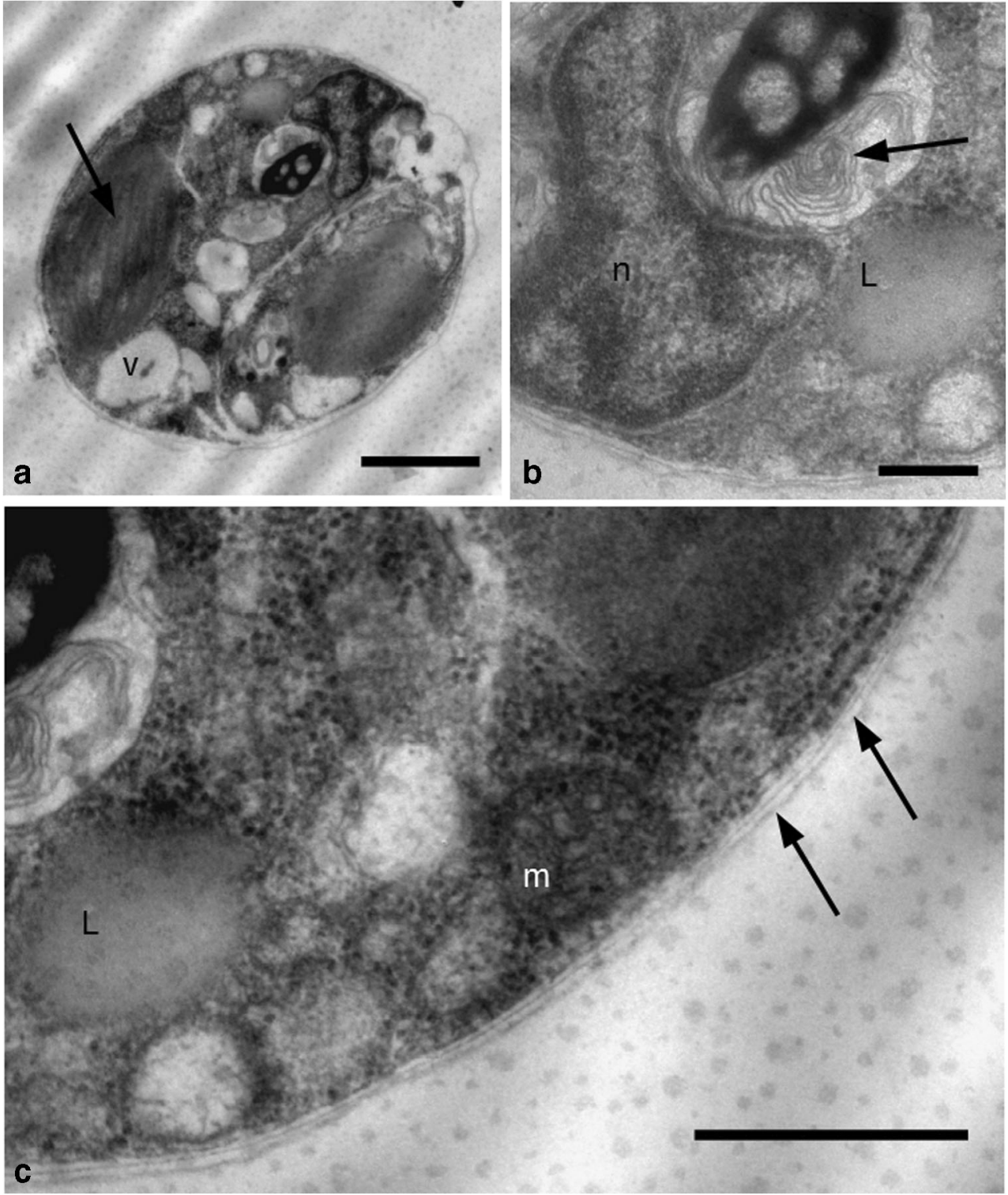

the section) about 300-400 nm of diameter were visible (Fig. $3 b)$. The wall structure was two layered and its thickness was $32.9 \mathrm{~nm}$ (SD $6.3 \mathrm{~nm} 62$ measurements) in average (Fig. 3c). Mitochondria showed tubular cristae and were often close to the plasma membrane, while the cytoplasm was occupied by a large number of ribosomes well distributed in the whole cell cytoplasm (Fig. 3c). Some vacuoles showed a modest autophagic activity (Fig. 4a and 4b). Some mitochondria, often observed close to the vacuoles and others close to the plasma membrane, showed an elongated shape (Fig. 4b), while some endoplasmic reticulum (ER) elements appeared dilated, apparently ending in a small vacuole (Fig. 4b). Some of the ERdilated elements appeared to reach the plasma membrane (Fig. 4c). Inside vacuoles, small multilamellar bodies and dark structures might form (Fig. 4c).

When starved in indoor culture, $N$. oceanica F\&M-M24 cells showed the most evident modifications at the level of the chloroplast. These organelles lost functional thylakoids whose membranes were transformed into multilamellar bodies (Fig. 5a). Vacuoles contained entire organelles and had increased electron density (Fig. 5a and 5b). In the starved cells, the walls changed to a single layer (grey to the electrons) of $37.8 \mathrm{~nm}$ (SD $2.8 \mathrm{~nm} 40$ measurements) in average. The difference in thickness with respect to the control was statistically significant after the Student's $t$ test $(p<0.01)$, as calculated with PAST (raw data in Supplementary file 1). Mitochondria were strongly electron dense and normally localised close to the plasma membrane (Fig. 5c).

In a later stage, the plastids did not show organised thylakoids (Fig. 6a) while few (1-2) lipid droplets occupied large part of the cytoplasm (Fig. 6a and 6b). Some small vacuoles were still visible at the periphery of the lipid droplets. In some vacuoles, some residual thylakoids appeared surrounded by apparently filamentous material (Fig. 6b). 
Fig. 4 Nannochloropsis control indoor cultivation. a The cytoplasm is occupied by large number of ribosomes. Some vacuoles show a modest autophagic activity. Thylakoids are associated in groups of 3 (arrow). Bar $=250 \mathrm{~nm}$. b Mitochondria have an elongated shape (arrow). Some endoplasmic reticulum elements appear to be dilated (asterisk), apparently ending in a small vacuole. Bar = $250 \mathrm{~nm}$. c Dilated endoplasmic reticulum elements appear to reach the plasma membrane. Some vacuoles form multilamellar bodies (asterisk) and dark structures (arrows). Bar $=250 \mathrm{~nm}$. Key to labelling: $\mathrm{c}$, chloroplast; er, endoplasmic reticulum; L, lipid droplet; LV, lamellate vesicle; $\mathrm{m}$, mitochondrion; n, nucleus; $v$, vacuole
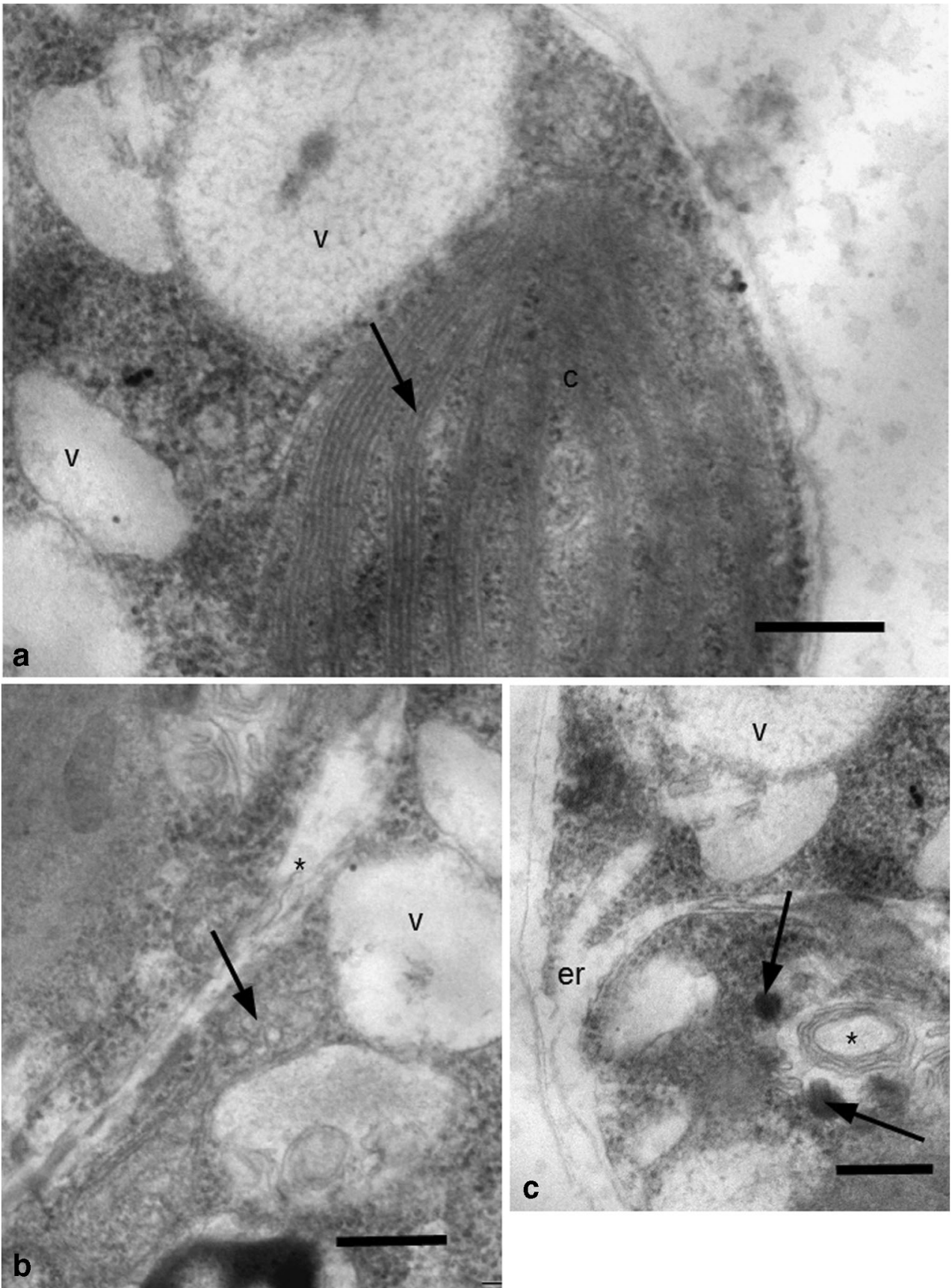

The transformation of the thylakoids started with the formation of circular membranes while in the plastid a granular content appeared (Fig. 6a). In some cell sections, a crystal about $800 \mathrm{~nm}$ long and $400 \mathrm{~nm}$ wide apparently formed by protein filaments appeared at the periphery (Fig. 6a).

The nucleus showed a very dense nucleoplasm (Fig. 6a). In a later phase, the thylakoids lost their individuality fusing into a lipid mass (Fig. 6b). In the scarcely electron dense cytoplasm, the ribosomes were rare (Fig. 6b).

The outdoor-cultivated Nannochloropsis cells (grown in $\mathrm{N}$-sufficient medium) did not show evident ultrastructural differences with respect to the indoor-cultivated cells (data not shown), while the starved outdoor cultivation showed a higher number of lamellate vacuoles (Fig. 7a and b) during intermediate steps of lipid accumulation while the chloroplasts were still visible including some pyrenoids (Fig. 7b). As in the indoor cultivation, the mitochondria increased largely their electron density (Fig. 7a). In the final step, there were little differences with respect to the indoor cultivation: the transformation of the thylakoids into a mass of multilamellar bodies and then a mass of electron dense lipids was observed also here (Fig. 7b). However, the presence of vacuoles containing 
Fig. 5 Starved Nannochloropsis indoor cultivation. a The modifications induced by starvation at the beginning are loss of thylakoids and the transformation of their membranes into multilamellar bodies (arrow). Vacuole contains entire organelles and has increased their electron density. Bar $=1 \mu \mathrm{m}$. b In a later stage, the plastids do not show organised thylakoids, while few (1-2) lipid droplets (asterisks) occupy most of the cytoplasm. Bar $=1 \mu \mathrm{m}$. c Some small vacuoles are still visible at the periphery of the lipid droplets. Mitochondria are electron dense and normally localised close to the plasma membrane. There is a single layer (arrows) outside the plasma membrane. Bar $=500 \mathrm{~nm}$. Key to labelling: $\mathrm{c}$, chloroplast; er, endoplasmic reticulum; L, lipid droplet; LV, lamellate vesicle; $\mathrm{m}$, mitochondrion; n, nucleus; v, vacuole
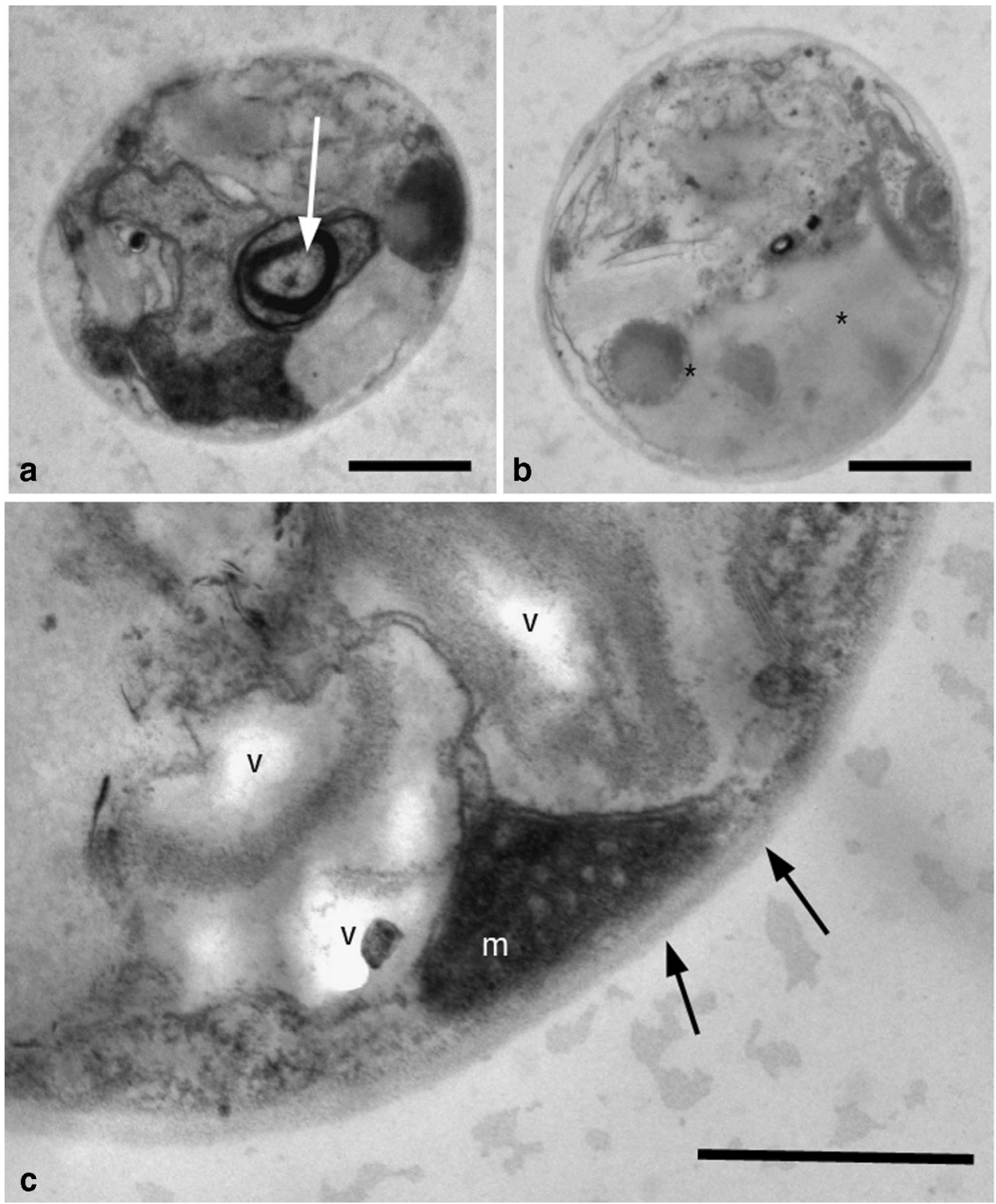

organelles was rare. In the final stage, the cell was almost completely filled by one large lipid containing vacuole and 2-3 small and more electron-transparent ones (Fig. 7c).

\section{Discussion}

Nannochloropsis oceanica F\&M-M24 was cultivated outdoors in a $10-\mathrm{L}$ pond in nitrogen-deprived medium. The average productivity of the whole period was $5.5 \mathrm{~g} \mathrm{~m}^{-2}$ day $^{-1}$. Nitrogen deprivation caused a significant decrease of proteins (from 40 to about 26\%), which was compensated by a similar increase of lipids (from 30 to more than 50\%). The same trend was observed in indoor cultures, although the increase in lipids (and the consequent decrease in proteins) was less gradual, reaching values very close to the final ones after 3 days. Although a comparison between the two experiments is difficult due to the different culture conditions and reactor geometry, it is very likely that the temporal differences in the accumulation of lipids can be attributed to the lack of the dark phase in indoor cultures. Indeed, during the inevitable light/dark cycle, lipid productivity of outdoor microalgae photoautotrophic cultivation is lowered by night biomass and lipid loss (Kato et al. 2019; Carneiro et al. 2020).

The capacity for ex novo lipid synthesis (mainly TAGs) seems to be a characteristic of oleaginous microalgae (Simionato et al. 2013), which, when grown under Ndeficiency (or other stress that limits growth), channel the excess of carbon and energy into storage lipid (mainly TAGs), at the expense of other cell components, particularly 

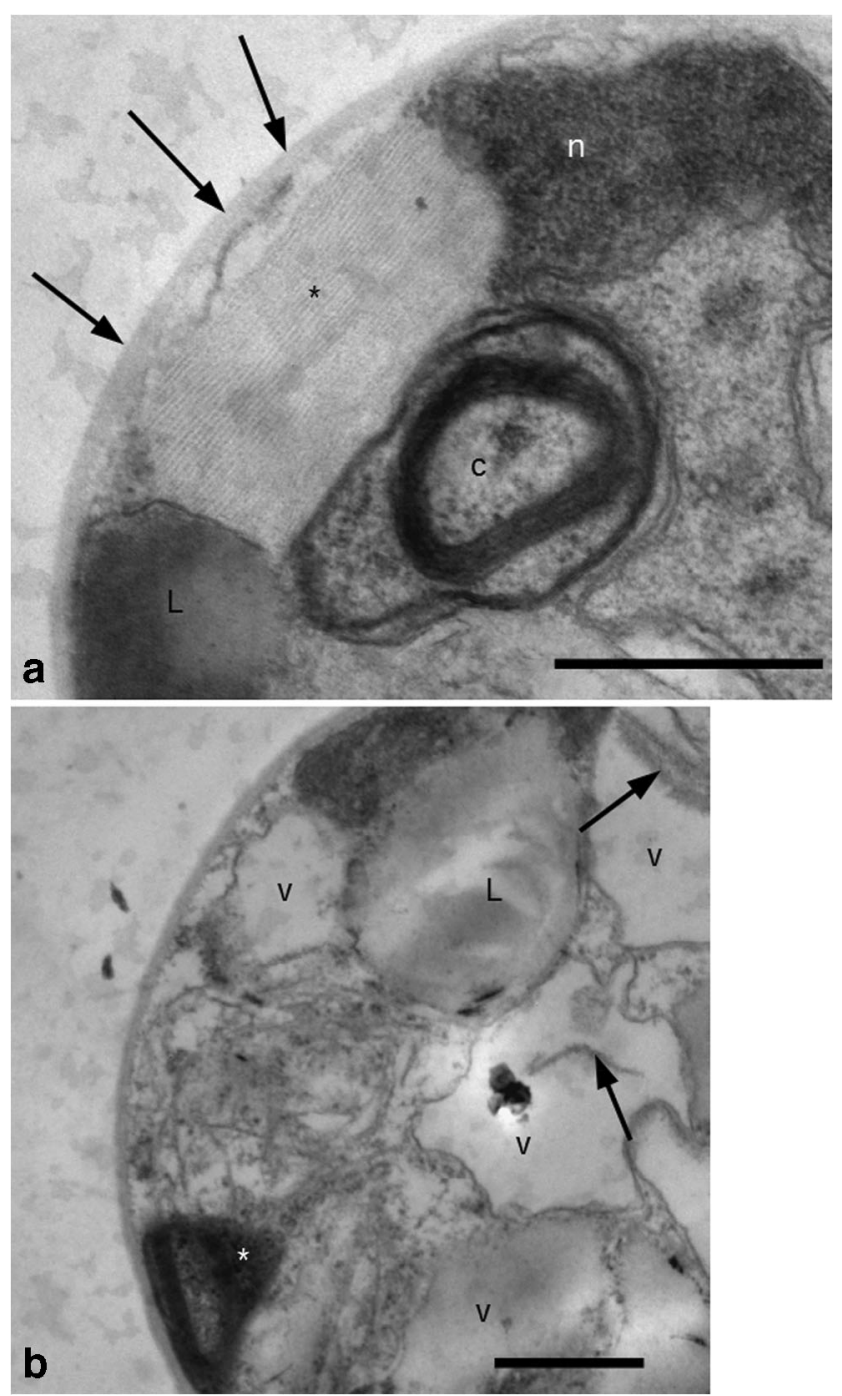

Fig. 6 Starved Nannochloropsis indoor cultivation. a The thylakoids start to form circular membranes, while in the plastid a granular content appears. In some cell sections, a crystal (asterisk) about $800 \mathrm{~nm}$ long and $400 \mathrm{~nm}$ wide apparently formed by protein filaments appears at the periphery. The nucleus shows a very dense nucleoplasm. Outside the plasma membrane, a layer (arrows) of $38.4 \mathrm{~nm}$ in average is present. Bar $=500 \mathrm{~nm}$. b In a later phase, the thylakoids lose their individuality fusing into a lipid mass (asterisk). Large part of the cytoplasm is occupied by small vacuoles containing intact membranes and residual thylakoids apparently surrounded by filamentous material (arrows). Bar $=500 \mathrm{~nm}$. Key to labelling: c, chloroplast; er, endoplasmic reticulum; L, lipid droplet; LV, lamellate vesicle; $m$, mitochondrion; $n$, nucleus; $v$, vacuole

proteins. The indoor and outdoor data clearly show the effect of nitrogen deprivation on lipid accumulation and confirm previous results with the same strain (Rodolfi et al. 2009).

The increase in lipid accumulation under nutrient limitation is a well-known process in the genus Nannochloropsis (Ajjawi et al. 2017; Sun et al. 2018). Surprisingly, the overexpression (Kang et al. 2005) or the knockout (Ajjawi et al. 2017) of a transcription factor may lead to further increase of lipid production without affecting biomass productivity.
Nitrogen starvation in $N$. oceanica F\&M-M24 causes changes in the chloroplasts by dismantling of the thylakoids that are destined to become first multilamellar bodies and eventually lipid droplets that will occupy large part of the cytoplasm. This mechanism of formation of the lipid droplets was already observed by van Doorn and Papini (2016) in angiosperms. A change in quantity of some chloroplast membrane lipids in condition of light stress was already observed by Wang (2020), showing that the chloroplast may be the key organelle in stress response in Nannochloropsis. We show here that in fact, part of the lipids may derive from thylakoids dismantling.

A thick cell wall may represent an obstacle to biocommodity extraction (Scholz et al. 2014). In N. gaditana, the wall is formed by an internal cellulosic layer and an outer hydrophobic algaenan layer (Scholz et al. 2014). Algaenan comprises saturated aliphatics with ether cross-links, resembling the cutan of vascular plants. The presence of fibrous extensions extending from the wall is considered typical of $N$. gaditana, for this reason assigned to the new genus Microchloropsis (Scholz et al. 2014) and Paraeustigmatos columelliferus (Fawley et al. 2019). This character is considered pleiomorphic in the algal class (Fawley et al. 2019). Nannochloropsis oceanica F\&M-M24 does not show these wall extensions and can be considered hence belonging to Nannochloropsis sensu stricto.

Wall thickness can vary in Nannochloropsis from 63 to $119 \mathrm{~nm}$, depending on the species, with $N$. oceanica (CCAP 849/10) reaching on the average a cell wall thickness of $111 \mathrm{~nm}$ (Beacham et al. 2014). In N. oceanica F\&M-M24, the wall thickness and structure changed depending on the physiological status, being two layered and about $32.9 \mathrm{~nm}$ in average in the control and changing to a single layer of $37.8 \mathrm{~nm}$ in average in the starved state (indoor cultivation). The difference was statistically significant. The more internal layer may correspond to the cellulose layer, while the outer one may be considered related to the algaenan component. The wall thickness in N. oceanica F\&M-M24 was much lower with respect to the strains analysed by Beacham et al. (2014). Both experiments were carried out indoors, even if Beacham et al. (2014) used a lower irradiance $(100 \mu \mathrm{mol}$ photons $\mathrm{m}^{-2} \mathrm{~s}^{-1}$, on a $16-\mathrm{h}: 8-\mathrm{h}$ light:dark cycle). For this reason, N.oceanica F\&M-M24 may present advantages from the point of view of cell content extraction. In fact, a thicker wall is related to the capability of microorganisms to resist mechanical rupture that is typical of biomass extraction, such as highpressure homogenisation (Middelberg 1995; Yap et al. 2016).

Moreover, the observed variation in structure and thickness would demonstrate that these characters are not simply genetically determined but also influenced by nutrients availability, as already stated by Jeong et al. (2017). These last authors showed that nitrogen starvation-induced cell wall increase in thickness and concurrently increase in the transcript 
Fig. 7 Starved Nannochloropsis outdoor cultivation. a

Intermediate step: chloroplast still visible. The lamellate vesicles are filling with lipids. Bar $=1 \mu \mathrm{m}$. b Intermediate step: pyrenoid still visible (arrow). Some lamellate vesicles are forming. Bar $=1 \mu \mathrm{m}$. c Final step. The larger part of the cytoplasm is occupied by a large lipid mass. A residual of chloroplast is still present, but the thylakoids are no longer distinguishable. Bar $=1 \mu \mathrm{m}$. Key to labelling: c, chloroplast; er, endoplasmic reticulum; L, lipid droplet; LV, lamellate vesicle; $\mathrm{m}$, mitochondrion; $\mathrm{n}$, nucleus; $\mathrm{v}$, vacuole
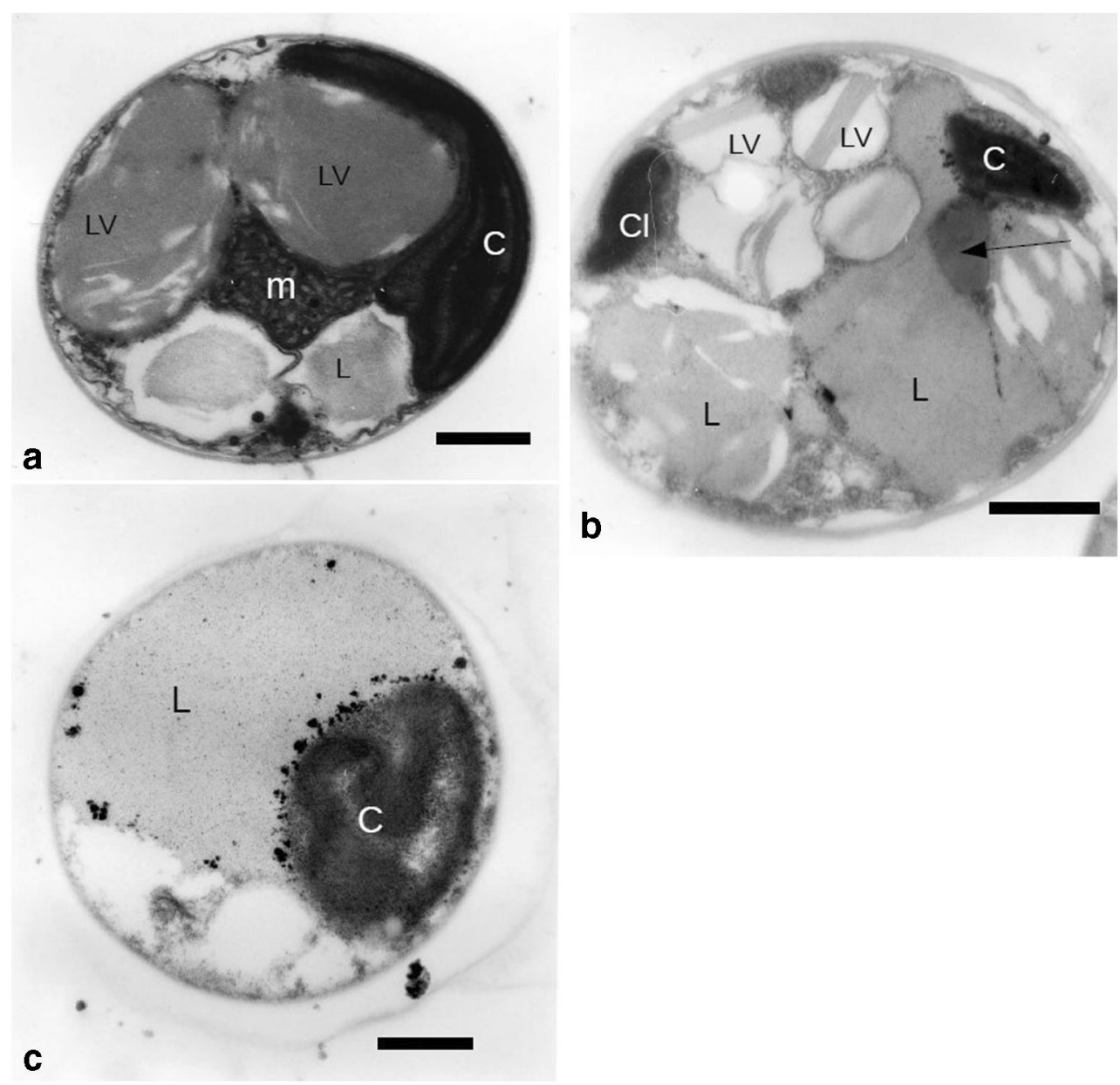

levels of genes coding for UDPG pyrophosphorylase and cellulose synthases, together with total cellulose content (Jeong et al. 2017).

The most striking changes in the cytoplasm are those related to the chloroplasts. The mechanism of recovery of the thylakoid membrane components passes through the formation of a ring of membranes within the chloroplast that later fuses to multilamellar bodies. The presence of thylakoids in the vacuoles indicates that autophagy is involved in chloroplast component recycling, as already suggested by Dong et al. (2013) for $N$. oceanica and, more in general, by Papini et al. (2014) and Papini and van Doorn (2015). The mechanism of vacuole formation is apparently related to the dilation of ER elements that is considered one of the main ways of formation of autophagic vacuoles (Papini et al. 2014). Since relatively small autophagic vacuoles are present even in the control, macroautophagy appears a normal mechanism of organelle recycling also in conditions of normal nutritional state.

While mitochondria in the N-sufficient medium appeared very similar to those already observed by Hashimoto (2004), specifically Fig. 1) in $N$. oculata, the large increase of their electron density in the starved case suggests that mitochondria are scarcely active in energy production and hence the cell is apparently consuming a low amount of energy. No specific investigation about the ultrastructure of mitochondria is available in ochrophytes or in heterokont protists. However, an electron dense matrix of the mitochondria has been related to damage due to hypoxia/ischaemia in mammal cells (Aliev et al. 2009; Liu et al. 2016). After Castejón and Viloria de Castejón (2004) and Solenski et al. (2002), an "intact" electron-dense mitochondrion of human cortical neurons is thought to represent calcium-overloaded mitochondria at some stage of degradation or injury. In our case, the increase in electron density of mitochondria matrix could be attributed to a lower availability of oxygen (hypoxia), possibly due to the lower cell wall permeability.

Moreover, the main use of acetyl-CoA is for fatty acid synthesis rather than in the Krebs cycle, and for this reason, mitochondria are more dedicated to citric acid cycle and boxidation to utilise the carbon skeletons derived from membrane lipids and proteins to produce additional fatty acids ( $\mathrm{Li}$ et al. 2014). Since the reduction in carbohydrates was only $13 \%$, the increase in lipid amount (almost $70 \%$ higher than the control) should derive from catabolism also of proteins and hence the change in mitochondria structure may be related to this type of biomolecules allocation. 
The increase in electron density of the nucleus is probably related to a progressive increase of the heterochromatin fraction and hence a reduction of the mRNA and rRNA production. Therefore, the number of ribosomes is largely reduced in the starved phase. Since the total content of proteins is reduced by $1 / 3$ at the end of the measurement, the large reduction in ribosomes populations does not allow the production of new polypeptides. Despite this blockade of translation, the observed filamentous crystal may represent a storage of protein at disposal for the cell when it will recover from translation and will need to rebuild the chloroplasts.

The outdoor-cultivated Nannochloropsis cells showed a higher number of lamellate vesicles during intermediate steps of lipid accumulation, while the autophagic activity in "normal" vacuoles was more difficult to be observed with respect to the indoor cultivation. Lamellate vesicles are a typical feature of Eustigmatophyceae. They were recorded around the pyrenoid or free in the cytoplasm by Maruyama et al. (1986), Santos (1990) and Santos and Leedale (1995) in several species of Nannochloropsis and they are considered related to the storage of reserve material by the cells, eventually ending in the formation of a lipid vacuole/droplet (Santos and Leedale 1995). Some variation in frequency of lamellate vesicles in Nannochloropsis was observed also by Suda et al. (2002), even if these authors did not assign any physiological explanation to this variation. After Schnepf et al. (1996) and Amaral et al. (2020), the lamellate vesicles may contain polysaccharides, possibly paramylon-like, but we show here that there is a continuum from lamellate vesicles towards lipid vacuoles, and the transformation of polysaccharides into lipids would require an enzymatic machinery in the vacuole both for catabolism of carbohydrates and for anabolism of lipids. Our data show that lamellate vesicles are more frequent in starved cells in outdoor cultivation, and hence, factors such as nitrogen depletion (related to lipid accumulation) and type of illumination may be involved.

\section{Conclusions}

The main effects of nitrogen starvation in $N$. oceanica F\&MM24 are the dismantling of the photosynthetic apparatus first by thylakoid disruption and later by macroautophagy, the formation of lipid droplets and the reduction in protein content. Besides, the increase in wall thickness and structure change might indicate that after starvation, the cells change towards a resistance state. However, $N$. oceanica F\&M-M24 appears to have a cell wall with a much lower thickness with respect to other species of Nannochloropsis investigated so far, and hence, it may be more easily disrupted to recover cell components. These modifications appear to be natural responses to reduction of availability of nutrients in order to survive in quiescence until an improvement of the environmental conditions allows a recovery of the cell and the rebuilding of the photosynthetic apparatus.

Supplementary Information The online version contains supplementary material available at https://doi.org/10.1007/s10811-021-02416-0.

Acknowledgements Open access funding provided by Università degli Studi di Firenze within the CRUI-CARE Agreement. The authors wish to thank Dr. Silvia Venturini for her valuable contribution to analyses of outdoor samples and Mr. Filippo Bacci for his excellent technical help in outdoor trials.

Author contribution Outdoor experiments were planned and performed by GCZ; indoor experiments were planned by MT, LR and BR and performed by BR; AP dealt with microscopy results. BR, GCZ and AP wrote the manuscript; LR and MT reviewed and approved it.

Funding Our investigation was financed with the Grant Fondi di Ateneo Papini 2018 and Mario Tredici 2018.

The authors thank the Regione Toscana (Par-FAS 2007-2013 Projects) for financial support to the Centro di Competenza VALORE (Florence, Italy), where part of the analyses have been carried out.

Declarations M.R. Tredici and L. Rodolfi have a financial interest in F\&M S.r.l. The other authors declare no conflicts of interest.

Open Access This article is licensed under a Creative Commons Attribution 4.0 International License, which permits use, sharing, adaptation, distribution and reproduction in any medium or format, as long as you give appropriate credit to the original author(s) and the source, provide a link to the Creative Commons licence, and indicate if changes were made. The images or other third party material in this article are included in the article's Creative Commons licence, unless indicated otherwise in a credit line to the material. If material is not included in the article's Creative Commons licence and your intended use is not permitted by statutory regulation or exceeds the permitted use, you will need to obtain permission directly from the copyright holder. To view a copy of this licence, visit http://creativecommons.org/licenses/by/4.0/.

\section{References}

Ajjawi I, Verruto J, Aqui M, Soriaga LB, Coppersmith J, Kwok K, Peach L, Orchard E, Kalb R, Xu W, Carlson TJ, Francis K, Konigsfeld K, Bartalis J, Schultz A, Lambert W, Schwartz AS, Brown R, Moellering ER (2017) Lipid production in Nannochloropsis gaditana is doubled by decreasing expression of a single transcriptional regulator. Nat Biotechnol 35:647-652

Aliev G, Palacios HH, Walrafen B, Lipsitt AE, Obrenovich ME, Morales L (2009) Brain mitochondria as a primary target in the development of treatment strategies for Alzheimer disease. Int J Biochem Cell Biol 41(10):1989-2004

Amaral R, Fawley KP, Němcová Y, Ševčíková T, Lukešová A, Fawley MW (2020) Toward modern classification of Eustigmatophytes. Including the description of Neomonodaceae fam. nov. and three new genera. J Phycol 56:630-648 
Beacham TA, Bradley C, White DA, Bond P, Ali ST (2014) Lipid productivity and cell wall ultrastructure of six strains of Nannochloropsis: implications for biofuel production and downstream processing. Algal Res 6:64-69

Bondioli P, Della BL, Rivolta G, Chini Zittelli G, Bassi N, Rodolfi L, Casini D, Prussi M, Chiaramonti D, Tredici MR (2012) Oil production by the marine microalgae Nannochloropsis sp. F\&M-M24 and Tetraselmis suecica F\&M-M33. Bioresour Technol 114:

Brennan L, Owende P (2010) Biofuels from microalgae - a review of technologies for production, processing, and extractions of biofuels and co-products. Renew Sustain Energy Rev 14:557-577

Capelli C, Ballot A, Cerasino L, Papini A, Salmaso N (2017) Biogeography of bloom-forming microcystin producing and nontoxigenic populations of Dolichospermum lemmermannii (Cyanobacteria). Harmful Algae 67:1-12

Carneiro M, Cicchi B, Maia IB, Pereira H, Zittelli GC, Varela J, Malcata FX, Torzillo G (2020) Effect of temperature on growth, photosynthesis and biochemical composition of Nannochloropsis oceanica, grown outdoors in tubular photobioreactors. Algal Research 49: 101923

Castejón OJ, Viloria de Castejón H (2004) Structural patterns of injured mitochondria in human oedematous cerebral cortex. Brain Injury 18:1107-1126

Dong HP, Williams E, Wang DZ, Xie ZX, Hsia RC, Jenck A, Halden R, Li J, Chen F, Place AR (2013) Responses of Nannochloropsis oceanica IMET1 to long-term nitrogen starvation and recovery. Plant Physiol 162:1110-1126

Dubois M, Gilles KA, Hamilton JK, Rebers PA, Smith F (1956) Colorimetric method for determination of sugars and related substances. Anal Chem 28:350-356

Fawley MW, Němcová Y, Fawley KP (2019) Phylogeny and characterization of Paraeustigmatos columelliferus. gen. et sp. nov. a member of the Eustigmatophyceae that may represent a basal group within the Eustigmatales. Fottea 19:107-114

Guillard RRL, Ryther JH (1962) Studies of marine planktonic diatoms. I. Cyclotella nana Hustedt, and Detonula confervacea (Cleve) Gran. Can J Microbiol 8(2):229-239

Halim R, Hill DRA, Hanssen E, Webley PA, Blackburn S, Grossman AR, Posten C, Martin GJO (2019) Towards sustainable microalgal biomass processing: anaerobic induction of autolytic cell-wall selfingestion in lipid-rich Nannochloropsis slurries. Green Chem 21: 2967-2982

Hammer O, Harper D, Ryan PD (2001) PAST: paleontological statistics software package for education and data analysis. Palaeontol Electron 4:1-9

Hashimoto H (2004) Mitochondrion-dividing ring in an alga Nannochloropsis oculata (Eustigmatophyceae, Heterokonta). Cytologia 69:323-326

Hong-Po D, Williams E, Wang D-Z, Xie Z-X, Hsia R-C, Jenck A, Halden R, Li J, Chen F, Place AR (2013) Responses of Nannochloropsis oceanica IMET1 to long-term nitrogen starvation and recovery. Plant Physiol 162:1110-1126

Jeong SW, Nam SW, HwangBo K, Jeong WJ, Jeong BJ, Chang YK, Park Y (2017) Transcriptional regulation of cellulose biosynthesis during the early phase of nitrogen deprivation in Nannochloropsis salina. Sci Rep 7:5264

Kang NK, Jeon S, Kwon S, Koh HG, Shin SE, Lee B, Choi GG, Yang JW, Jeong BR, Chang YK (2005) Effects of overexpression of a bHLH transcription factor on biomass and lipid production in Nannochloropsis salina. Biotechnol Biofuels 8:1-13

Kato Y, Fujihara Y, Vavricka CJ, Chang J-S, Hasunuma T, Kondo A (2019) Light/dark cycling causes delayed lipid accumulation and increased photoperiod-based biomass yield by altering metabolic flux in oleaginous Chlamydomonas sp.. Biotechnol Biofuels 12(1)

Li J, Danxiang H, Dongmei W, Kang N, Jing J, Li W, Xiaoyan J, Shi H, Jie C, Yantao L, Qiang H, Jian X (2014) Choreography of transcriptomes and lipidomes of Nannochloropsis reveals the mechanisms of oil synthesis in microalgae. Plant Cell 26:1645-1665

Liu P, Zou Chen K, Zhou Q, Gao Y, Huang Y, Zhu J, Zhang Q, Mi M (2016) Dihydromyricetin improves hypobaric hypoxia-induced memory impairment via modulation of SIRT3 signaling. Mol Neurobiol 53:7200-7212

Long RD, Abdelkader E (2011) Mixed-polarity azeotropic solvents for efficient extraction of lipids from Nannochloropsis microalgae. Am J Biochem Biotechnol 7:70-73

Lowry OH, Rosebrough NJ, Farr AL, Randall RJ (1951) Protein measurement with the Folin phenol reagent. J Biol Chem 193:265-275

Marsh JB, Weinstein DB (1966) Simple charring method for determination of lipids. J Lipid Res 7(4):574-576

Maruyama I, Nakamura T, Ando Y, Maeda T (1986) Identification of the alga known as "marine Chlorella" as a member of the Eustygmatophyceae. Jap J Phycol 34:319-325

McMillan JR, Watson IA, Ali M, Jaafar W (2013) Evaluation and comparison of algal cell disruption methods: microwave, waterbath, blender, ultrasonic and laser treatment. Appl Energy 103:128-134

Middelberg APJ (1995) Process-scale disruption of microorganisms. Biotechnol Adv 13:491-551

Milano J, Chyuan Ong H, Masjuki H, Chong WT, Kee Lam M, Kwan Loh P, Vellayan V (2016) Microalgae biofuels as an alternative to fossil fuel for power generation. Renew Sust Energy Rev 58:180 197

Ndimba BK, Ndimba RJ, Johnson TS, Waditee-Sirisattha R, Baba M, Sirisattha S, Shiraiwa Y, Agrawal GK, Rakwal R (2013) Biofuels as a sustainable energy source: an update of the applications of proteomics in bioenergy crops and algae. J Proteom 93:234-244

Papini A, Simeone MC (2010) Forest resources for second generation biofuels production. Scand J Forest Res 25:126-133

Papini A, van Doorn WG (2015) Crystalloids in apparent autophagic plastids: remnants of plastids or peroxisomes? J Plant Physiol 174: $36-40$

Papini A, Mosti S, van Doorn WG (2014) Classical macroautophagy in Lobivia rauschii (Cactaceae) and possible plastidial autophagy in Tillandsia albida (Bromeliaceae) tapetum cells. Protoplasma 251: 719-725

Papini A, Fani F, Belli M, Niccolai C, Tani C, Di Falco P, Nuccio C, Lazzara L (2017) Structural and ultrastructure changes show an increase of amoeboid forms in Heterosigma akashiwo (Raphidophyceae). during recovery after nutrient depletion. Plant Biosyst 151:965-973

Papini A, Gonnelli C, Tani C, Di Falco P, Wolswijk G, Santosuosso U, Nuccio C, Schiff S, Lazzara L, Menicucci F, Belli M, Habte Karssa T, Ballini R (2018) Autophagy induced by heavy metal and starvation stress in microalgae. Phytomorphology 68:7-12

Rios LF, Klein BC, Luz LF, Maciel Filho R, Wolf Maciel MR (2015) Nitrogen starvation for lipid accumulation in the microalga species Desmodesmus sp. Appl Biochem Biotechnol 175:469-476

Rodolfi L, Chini Zittelli G, Bassi N, Padovani G, Biondi N, Bonini G, Tredici MR (2009) Microalgae for oil: strain selection. induction of lipid synthesis and outdoor mass cultivation in a low-cost photobioreactor. Biotechnol Bioeng 102:100-112

Santos LMA (1990) Cytology and ultrastructure of Eustigmatophyceae. $\mathrm{PhD}$ Thesis. The University of Leeds. 
Santos LMA, Leedale GF (1995) Some notes on the ultrastructure of small azoosporic members of the algal class Eustigmatophyceae. Nova Hedwigia 60:219-225

Schnepf E, Niemann A, Wilhelm C (1996) Pseudostaurastrum limneticum. a Eustigmatophycean alga with astigmatic zoospores: morphogenesis. fine structure. pigment composition and taxonomy. Arch Protistenkd 146:237-249

Scholz MJ, Weis TL, Jinkerson RE, Jing J, Roth R, Goodenough U, Posewitz MC, Gerken HG (2014) Ultrastructure and composition of the Nannochloropsis gaditana cell wall. Eukaryot Cell 13:1450 1464

Simionato D, Block MA, La Rocca N, Jouhet J, Maréchal E, Finazzi G, Morosinotto T (2013) The response of Nannochloropsis gaditana to nitrogen starvation includes de novo biosynthesis of triacylglycerols. a decrease of chloroplast galactolipids. and reorganization of the photosynthetic apparatus. Eukaryot Cell 12:665-676

Slade R, Bauen A (2013) Micro-algae cultivation for biofuels: cost, energy balance, environmental impacts and future prospects. Biomass Bioenergy 53:29-38

Solenski NJ, diPierro CG, Trimmer PA, Kwan AL, Helms GS (2002) Ultrastructural changes of neuronal mitochondria after transient and permanent cerebral ischemia. Stroke 33:816-824

Spurr AR (1969) A low-viscosity epoxy resin embedding medium for electron microscopy. J Ultrastruct Res 26(1-2):31-43
Suda S, Atsumi M, Miyashita H (2002) Taxonomic characterization of a marine Nannochloropsis species. $N$. oceanica sp. nov. (Eustigmatophyceae). Phycologia 41:273-279

Sun X, Ren L, Zhao Q, Ji X-J, Huang H (2018) Microalgae for the production of lipid and carotenoids: a review with focus on stress regulation and adaptation. Biotechnol Biofuels 11:272

van Doorn WG, Papini A (2016) Plastid degeneration in Tillandsia albida (Bromeliaceae) and Lobivia rauschii (Cactaceae) provides evidence about the origin and destiny of multilamellar bodies in plants. Phytomorphology 66:103-112

Wang B, Jia J (2020) Photoprotection mechanisms of Nannochloropsis oceanica in response to light stress. Algal Res 46:101784

Yap BHJ, Crawford SA, Dagastine RR, Scales PJ, Martin GJO (2016) Nitrogen deprivation of microalgae: effect on cell size, cell wall thickness, cell strength, and resistance to mechanical disruption. J Ind Microbiol Biotechnol 43:1671-1680

Zanella L, Vianello F (2020) Microalgae of the genus Nannochloropsis: Chemical composition and functional implications for human nutrition. J Funct Food 68:103919

Publisher's note Springer Nature remains neutral with regard to jurisdictional claims in published maps and institutional affiliations. 